\title{
无人机遥感技术在测绘工程测量中的应用
}

\section{Application of UAV Remote Sensing Technology in Surveying and Mapping Engineering}

\author{
冯章健 \\ Zhangjian Feng \\ 广东省有色地质测绘院 中国·广东 广州 510000 \\ Guangdong Nonferrous Geological Surveying and Mapping Institute, Guangzhou, Guangdong, 510000, China
}

摘 要: 论文通过对无人机遥感技术的概念、优势及其在测绘工程测量中的应用进行了深入研究, 并结合工程案例探讨了无 人机遥感技术的实际应用, 以期为相关从业人员提供参考。

\begin{abstract}
In this paper, the concept, advantages of UAV remote sensing technology and its application in surveying and mapping engineering survey are deeply studied, and the practical application of UAV remote sensing technology is discussed in combination with engineering cases in order to provide reference for relevant practitioners.
\end{abstract}

关键词: 无人机遥感技术;测绘工程; 应用

Keywords : UAV remote sensing technology; surveying and mapping engineering; application

DOI : 10.36012/etr.v2i8.2507

\section{1 无人机遥感技术简介}

无人机遥感技术是由遥感技术、无人机技术、GPS 技术 等多种技术联用的一项测绘技术，凭借其测量准确性好、测 绘效率高等优势, 在工程建设、地质灾害调查及国土资源规 划等方面得到了广泛的应用。利用无人机遥感技术进行测绘 工程测量工作, 具体实施流程主要包括以下几点。第一,无人 机展开航空摄影; 第二, 在内业测绘成果的基础上进行空三 加密和立体测图; 第三, 以内业测绘成果为依据进行补测与 调绘, 编辑并提交最终测绘成果。

\section{2 无人机遥感技术的特点}

\section{1 测绘效率高}

从测绘工程测量的整体方向来看, 无人机遥感技术的应 用, 能够对地球表面的各个区域进行全方位的详细勘查和测 绘, 能够有效避免一些地质灾害等问题, 还能有效提高复杂 条件下的工程测量质量及其效率, 实现测绘工作的数字化和 智能化。

\section{2 数据处理快}

测绘工程测量中, 在指定区域勘测时会产生大量数据,
因此, 数据处理是一项庞大的工作, 要求相关工作人员对这 些数据进行全面收集和准确统计, 并将其以图像的形式进行 展示, 帮助测绘人员详细了解工程具体情况, 给后续工作提 供数据支持。同时,无人机遥感技术能够利用遥感技术快速 提供可靠的效益, 给救援工作提供有效的帮助, 并能够对测 量数据快速分类处理, 从而能够为救援工作的开展制订相应 救援计划,具有重要意义。

\section{3 灵活性强}

无人机遥感技术具有体积更小、升降时间更短、对场地 要求较低等优势, 并且具有良好的灵活性, 能够更好地满足 测绘工程测量要求 ${ }^{[1]}$ 。同时, 无人机遥感技术操作简单、工作 效率较高, 并且随着科技的不断发展, 其运行成本也越来越 低,在许多地势复杂、位置偏远的地区都得到了良好应用, 极 大地节约了人力物力, 能够有效满足短时间勘测要求。

\section{3 无人机遥感技术在测绘工程测量中的具体 应用}

\section{1 大比例尺地形图测绘}

大比例尺地形图测绘需要对正射影像图纸和基础地形 
进行测量, 并根据实际测量结果绘制成图。在利用无人机遥 感技术进行地形图测绘的过程中, 将所获的影像数据在 ArcGIS 中建立多个图层, 并将外业采集中地物特征点绘制到 ArcGIS 中, 获得精确度更高的矢量化数据结果, 有效提高了 地形图的测绘效率 ${ }^{[2]}$

\section{2 无人机遥感技术在低空作业中的应用}

无人机遥感技术在低空进行航拍摄像, 能够更好地发 挥自身优势, 高效快速地获取资料。中国已经成功开发并 应用了无人飞艇低空航测系统开展低空作业, 该系统采用 了具有自稳定、自检校功能数码相机系统, 通过检校软件 和像片重叠关系, 能够有效减少无人机机身变形引起的测 量误差。

\section{3 矿山测量中的应用}

由于矿山地形条件复杂, 并且存在一定开采危险性, 可能对周围环境造成不利影响, 因此, 需要利用无人机遥 感技术对周边地形环境进行勘查, 对矿山地理信息数据进 行收集, 从而有效提高矿山开采水平和效率。同时, 无人机 遥感技术在矿山保护和环境治理方面也能充分发挥作用, 其应用各种雷达传感器、多光谱传感器等设备, 获取数据 并展开定性和定量分析, 为矿山管理者进行矿山环保决策 提供参考。

\section{4 无人机遥感技术在测绘测量中的应用实例}

\section{1 无人机遥感测绘测量航线设计}

在本工程中, 根据测绘现场风向、范围及河道形状等因 素, 设定航测高度为 $400 \mathrm{~m}$, 航线设计为 4 条, 设定测绘成图 比例为 $1: 1000$, 重叠度为 0.8 。同时, 由于本工程测量过程中 航向重叠度、旁向重叠度都相对偏高, 利用无人机遥感技术 能够有效降低飞行过程中风速、风向对测量结果的影响。当 上述准备工作完成后, 则需要等待适当时机进行测量, 并时 刻对航拍无人机和相机精度进行检查和维护, 确保所有设备 在测量过程中都处于最佳状态。

\section{2 无人机遥感快速拼接与像控测量}

由于本工程河道测量特征点较多, 导致获得像控测量点 较多, 并且摄像幅度较小。当获得航摄影像后, 需要快速检查 摄像质量, 并有针对性地对像片进行畸变预处理。随后根据 每张像片的 POS 数据, 实现影像资料的快速拼接, 以便完善 测绘设计方案 ${ }^{[3]}$ 。在本工程的测绘工作中,共设置了 4 条基准 线, 在相邻区域间设定了公共像控点, 并针对地势复杂或有
树木遮挡的位置增设了像控点, 最终设置了 26 个测控点, 并 利用导航软件规划好测绘方案, 有效提高了测绘效率, 降低 了人工投入, 提高了测绘工程质量。

\section{3 空中三角测量}

由于本工程无人机遥感航线为 $\mathrm{T}$ 型, 选择东西两条航线 作为本次构架航线, 通过 POS 数据形成航带, 自动匹配连接 点并挑选出粗差。同时, 还需要检查测区范围内连接点的分 布情况是否均匀, 这跟测量数据连接强度密切相关, 通过评 查计算后, 对点精度和基本定向点精度进行检查, 结果如表 1 所示。

\section{表 1 点精度和基本定向点精度检查}

\begin{tabular}{c|c|c|c|c}
\hline 成图比例尺 & 统计类型 & 中误差 & 最大残差 & 规范限差 \\
\hline \multirow{3}{*}{$1: 1000$} & \multirow{2}{*}{ 定向点 } & 0.5 & 0.15 & 0.6 \\
\cline { 3 - 5 } & & 0.11 & 0.21 & 0.26 \\
\cline { 2 - 5 } & \multirow{2}{*}{ 检查点 } & 0.11 & 0.24 & 1.0 \\
\cline { 3 - 5 } & & 0.19 & 0.37 & 0.4 \\
\hline
\end{tabular}

从上表可以看出, 部分点存在较大的测量误差, 这一现 象的原因在于外业实测检查时部分点的位置选择不好, 导致 定位不够准确, 影响测量结果。

\section{4 无人机遥感测绘测量精度分析}

对本工程测量精度进行检查, 需要对 25 个无投影差地 物特征点进行野外 RTK 实测, 并将其与 DOM 进行精度评 定。由于工程要求对高程精度进行实测, 因此不进行高程精 度的评定, 获得平面中误差为 0.28 , 高程中误差为 0.3 , 可以 看出此次测量结果满足 1:1000 比例尺地形图测绘要求, 充 分展现了无人机遥感技术在测绘工程测量中能够获得良好 的应用效果。

\section{5 结语}

由于目前对测绘事业的技术要求逐步提高, 对测绘工程 精准度、测绘范围的标准也在不断的提高。无人机技术的不断 完善, 将是弥补人工测绘缺点的主要方式, 将会极大完善测绘 工程整体质量, 对未来的测绘工程发展具有重要的意义。

\section{参考文献}

[1] 谭程华.测绘工程测量中无人机遥感技术的应用[J].建材与装 饰,2019(3):241-242.

[2] 陈彦君. 无人机遥感技术在测绘工程测量中的实践[J].电子测 试,2019(9):78-79.

[3] 吴泽强. 无人机遥感技术在测绘工程测量的应用分析 [J]. 智能城 市,2020,6(2):52-53. 